\title{
Blood biomarkers of nicotine-induced toxicity in healthy males
}

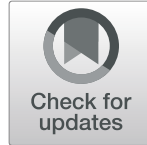

\author{
Mai Mohamed Mahrous ${ }^{1}$, Usama Mohamed El-Barrany ${ }^{1}$, Manal Mohy El-Din Ismail ${ }^{1}$, Iman Fawzy Gaballah ${ }^{1 *}$ and \\ Laila Ahmed Rashed ${ }^{2}$
}

\begin{abstract}
Background: Smoking enhances oxidative stress by causing an oxidant/antioxidant imbalance in the body leading to deleterious effects on various tissues and organs. 8-hydroxy-2'-deoxyguanosine (8-OHdG) is a predominant form of free radical-induced oxidative lesions, and is widely used as a biomarker of oxidative stress.

Objectives: This study aimed to estimate blood 8-OHdG level in active, passive and non-smokers and its relation with some lifestyle determinants as well as to assess smoking effects on oxidant/antioxidant status.

Participants and methods: The current work included 90 male participants who were classified into 3 groups; 20 non-smokers, 30 passive smokers, and 40 active smokers. Data were collected by answering a premade questionnaire. Peripheral venous blood samples were withdrawn then 8-OHdG, cotinine, superoxide dismutase (SOD), and total antioxidant capacity (TAC) levels were estimated in plasma using ELISA kits, while malondialdehyde (MDA) was estimated by colorimetry.

Results: There were highly statistically significant higher levels of 8-OHdG, cotinine and MDA and lower levels of SOD and TAC in active smokers compared to both passive and non-smokers $(p<0.001)$ whereas, no statistically significant difference between passive and non-smokers was detected $(p>0.05)$. There were no significant differences between 8-OHdG level and smoking habits, age, exercise, tea and coffee consumption, and body mass index (BMI) among the 3 studied groups.

Conclusion: Smoking induces oxidative stress not only through the production of reactive oxygen radicals and increasing blood 8-OHdG levels but also through weakening of the antioxidant defense systems. Further studies are required to reach a consensus on the background level of $8-\mathrm{OHdG}$ and understand which factors determine it and to further differentiate between passive and non-smokers.
\end{abstract}

Keywords: Smoking, Oxidative, Stress, Antioxidant, 8-OHdG

\section{Background}

Cigarette smoking is one of the most common habits of the modern world. It is reported by the World Health Organization (WHO) that 30\% of the world's population over the age of 15 smoked cigarettes (Kulikowska-Karpińska and Czerw 2015).

Oxidative stress caused by smoking reflects an imbalance between the systemic manifestation of reactive oxygen species (ROS) and a biological system's ability to promptly detoxify the reactive intermediates or to repair

\footnotetext{
*Correspondence: imangabo@kasralainy.edu.eg; dr.iman.gaballah@gmail.com ${ }^{1}$ Department of Forensic Medicine and Clinical Toxicology, Faculty of Medicine, Cairo University, Cairo, Egypt

Full list of author information is available at the end of the article
}

the subsequent harm. Disturbances in the typical redox condition of cells can cause lethal impacts through the creation of peroxides and free radicals that harm all segments of the cell, including lipids, proteins, and DNA (Andersson 2017). The potential damage caused by free radicals found in tobacco smoke is minimized by biological antioxidant mechanisms including enzymatic and non-enzymatic reactions (Mahapatra et al. 2008). Antioxidant enzymes such as superoxide dismutase are an important line of defense against oxidative cell damage preventing lipid peroxidation and overproduction of malondialdehyde (Kamceva et al. 2016). Total antioxidant capacity is frequently used to assess the cumulative effects of antioxidants in a biological sample and can 
evaluate the antioxidant response against the free radicals produced (Rubio et al. 2016).

Damage to DNA is indicated by increased levels of 8OHdG, a repair product of the oxidation of guanine in DNA. It can be detected in human tissues, blood or urine, and is considered a reliable and pivotal biomarker of generalized and cellular oxidative stress (Liu et al. 2018). Also, it is an important biomarker for various pathological conditions such as aging, carcinogenesis, neurodegenerative, and cardiovascular diseases as estimated by quantitative analytical techniques in blood and urine (Valavanidis et al. 2009).

Cotinine, a metabolite of nicotine, is a specific biomarker of tobacco smoking exposure. Using this biomarker increases the measured precision for the association between 8-OHdG and smoking (Lu et al. 2014).

Therefore, the current study aimed to investigate nicotine-induced oxidative stress by estimating blood 8OHdG level and assessing its relation with some lifestyle determinants. Oxidant stress marker (MDA) and antioxidant defense enzyme (SOD) as well as cotinine and TAC levels were also measured.

\section{Participants and methods}

The current study is a case control study in which healthy male participants were randomly selected and interviewed after taking their informed consent as well as obtaining the approval of the study design from the Research Ethics Committee at KasrAlainy, Faculty of Medicine.

The study represented collaboration between Forensic Medicine and Clinical Toxicology Department and Medical Biochemistry Department, Faculty of Medicine, Cairo University, Egypt. The study was conducted according to the Declaration of Helsinki (World Medical Association 2013).

A premade Arabic questionnaire was answered; it included questions about socio-demographic data, smoking status, space ventilation, exercise, tea, coffee, energy drinks, and alcohol consumption, present, past, and family history of diseases.

\section{Inclusion criteria}

Ninety male participants, aged 20-60 years, were enrolled in the study. According to Lodovici et al. (2005), participants were classified according to their smoking history into three groups:

- Non-smokers (20 cases) never smoked and not exposed to environmental tobacco smoking (ETS).

- Passive smokers (30 cases) non-smokers but exposed to ETS in poorly ventilated areas for $>3 \mathrm{~h} /$ day in the year.
- Active smokers (40 cases) > 3 cigarettes/day for over 1 year.

\section{Exclusion criteria}

- Medical disorders diabetes, autoimmune diseases, cardiovascular and neurodegenerative diseases, hepatic and renal diseases, infections, cancer, chronic skin ulcerations, and endocrine and hematologic disorders (Chen et al. 2017).

- Medications steroids, non-steroidal antiinflammatory, diuretics, anticonvulsants, antidepressants, antibiotics, and vitamin supplementation.

- Participants receiving mutagenic and carcinogenic drugs, chemotherapy, and/or radiotherapy.

- Participants living near or working in industrial areas.

\section{Study measurements and estimations}

Body weight and height were measured for all participants. Peripheral venous blood samples were withdrawn (3 ml) into EDTA tubes. The collected whole blood was centrifuged for approximately $20 \mathrm{~min}$ at $1000-3000 \mathrm{rpm}$ (rpm) within $30 \mathrm{~min}$ after collection. The supernatant was collected carefully and stored at $-80^{\circ} \mathrm{C} .8-\mathrm{OHdG}$, cotinine, SOD, and TAC levels were estimated in plasma using ELISA kits, while MDA was estimated by colorimetry.

\section{ELISA kits}

Human 8-OHdG ELISA kit (Cat No. MBS267161) was provided by My Biosource Company, USA. According to manual instructions provided by the applied kit, doublesandwich ELISA technique was used where the precoated antibody was human 8-OHdG monoclonal antibody and the detecting antibody was polyclonal antibody which was biotin-labeled. Samples and biotin labeling antibody were added into ELISA plate wells and washed out with phosphate-buffered saline (PBS) followed by avidin-peroxidase conjugates which were added in order.

The reactant was washed out thoroughly by PBS, tetramethylbenzidine (TMB) substrate was then used for coloring. It turned blue in peroxidase and finally yellow under the action of acid. Human cotinine ELISA kit (Cat No. MBS019457) was provided by My Biosource Company, USA, while Human SOD and TAC ELISA kits (Cat No. BYEK1111) were provided by Chongqing Biospes Company, China. According to manual instructions provided by the applied kits, purified antisubstance antibody was pre-coated onto well plates and the horseradish peroxidase (HRP) conjugated antisubstance antibody was used as detection antibodies. Standards, test samples, and HRP conjugated detection antibody were added to the wells subsequently, mixed 
Table 1 Baseline demographic characteristics of the studied groups

\begin{tabular}{|c|c|c|c|c|c|c|c|}
\hline \multirow{2}{*}{$\frac{\text { Variable }}{\text { Age (years) }(\text { mean } \pm S D)}$} & \multicolumn{2}{|c|}{ Non-smokers $(n=20)$} & \multicolumn{2}{|c|}{ Passive smokers $(n=30)$} & \multicolumn{2}{|c|}{ Active smokers $(n=40)$} & \multirow{2}{*}{$\frac{p \text { value }}{0.655}$} \\
\hline & 31. & & 34. & & 32.5 & & \\
\hline Residence & $n$ & $\%$ & $n$ & $\%$ & $n$ & $\%$ & 0.069 \\
\hline Urban & 15 & 75 & 13 & 43.3 & 25 & 62.5 & \\
\hline Rural & 5 & 25 & 17 & 56.7 & 15 & 37.5 & \\
\hline Occupation & $n$ & $\%$ & $n$ & $\%$ & $n$ & $\%$ & $0.016^{*}$ \\
\hline Physical & 11 & 55 & 24 & 80 & 35 & 87.5 & \\
\hline Mental & 9 & 45 & 6 & 20 & 5 & 12.5 & \\
\hline Educational level & $n$ & $\%$ & $n$ & $\%$ & $n$ & $\%$ & $0.016^{*}$ \\
\hline Low & 3 & 15 & 10 & 33.3 & 16 & 40 & \\
\hline Moderate & 8 & 40 & 13 & 43.3 & 21 & 52.5 & \\
\hline High & 9 & 45 & 7 & 23.3 & 3 & 7.5 & \\
\hline
\end{tabular}

*Significant $p \leq 0.05$

$S D$ standard deviation

and incubated, then, the unbound conjugates were washed away with wash buffer. Tetramethylbenzidine substrates (A and B) were used to visualize HRP enzymatic reaction. It is catalyzed by HRP to produce a blue color product that changes into yellow after adding acidic stop solution. The density of yellow was proportional to the substance amount of sample captured in plate (Mamsen et al. 2010; Gao et al. 2018; AntunesLopes et al. 2018).

Calculation: Absorbance of the optical density (O.D.) was read at $450 \mathrm{~nm}$ in a microplate reader and then the concentration of substance was calculated.

Relative O.D.450 = O.D.450 of each well-O.D.450 of blank/control well

- The standard curve can be plotted as the relative O.D. 450 of each standard solution $(Y)$ versus the respective concentration of the standard solution $(X)$. A line was drawn to connect each coordinate point of standard solution. Sample concentrations were found by checking sample O.D. reading. It is recommended to employ the professional curve software (e.g., curve expert 1.3) to analyze and compute the results.

\section{Colorimetric method}

Malondialdehydecolorimetric kit (Cat No. MD 25 29) was provided by Biodiagnostic Company, Egypt. According to manual instructions provided by the applied kit, thiobarbituric acid (TBA) reacted with MDA in acidic medium at $95{ }^{\circ} \mathrm{C}$ for $30 \mathrm{~min}$ to form TBA-reactive product, and this is a sensitive assay method for lipid peroxidation (Aboutaleb et al. 2019).

- Calculation: The absorbance of sample $\left(A_{\text {sample }}\right)$ was read against blank and standard against water at 534

Table 2 Lifestyle factors of the studied groups

\begin{tabular}{|c|c|c|c|c|c|c|c|}
\hline \multirow{2}{*}{$\begin{array}{l}\text { Variable } \\
\text { Exercise }\end{array}$} & \multicolumn{2}{|c|}{ Non-smokers $(n=20)$} & \multicolumn{2}{|c|}{ Passive smokers $(n=30)$} & \multicolumn{2}{|c|}{ Active smokers $(n=40)$} & \multirow{2}{*}{$\begin{array}{r}p \text { value } \\
0.319\end{array}$} \\
\hline & $n$ & $\%$ & $n$ & $\%$ & $n$ & $\%$ & \\
\hline No & 19 & 95 & 29 & 96.7 & 35 & 87.5 & \\
\hline Yes & 1 & 5 & 1 & 3.3 & 5 & 12.5 & \\
\hline \multirow[t]{3}{*}{ Tea (cups/day) (mean \pm SD) } & Min. & Max. & Min. & Max. & Min. & Max. & $<0.001^{* *}$ \\
\hline & 0 & 7 & 0 & 10 & 0 & 20 & \\
\hline & \multicolumn{2}{|c|}{$2.06 \pm 1.66$} & \multicolumn{2}{|c|}{$2.75 \pm 2.16$} & \multicolumn{2}{|c|}{$5.13 \pm 3.82$} & \\
\hline \multirow[t]{3}{*}{ Coffee (cups/day) (mean \pm SD) } & Min. & Max. & Min. & Max. & Min. & Max. & $0.052^{*}$ \\
\hline & 0 & 1 & 0 & 1 & 0 & 5 & \\
\hline & \multicolumn{2}{|c|}{$0.16 \pm 0.37$} & \multicolumn{2}{|c|}{$0.08 \pm 0.21$} & \multicolumn{2}{|c|}{$0.61 \pm 1.4$} & \\
\hline BMI $\left(\mathrm{kg} / \mathrm{m}^{2}\right)($ mean $\pm \mathrm{SD})$ & \multicolumn{2}{|c|}{$29.19 \pm 4.79$} & \multicolumn{2}{|c|}{$26.81 \pm 4.49$} & \multicolumn{2}{|c|}{$24.43 \pm 4.34$} & $<0.001^{* *}$ \\
\hline
\end{tabular}


Table 3 Mean levels of the measured biochemical parameters among the studied groups

\begin{tabular}{|c|c|c|c|c|c|}
\hline Variable & Non-smokers $(n=20)$ & Passive smokers $(n=30)$ & Active smokers $(n=40)$ & Total $(n=90)$ & $p$ value \\
\hline 8-OHdG (ng/ml) (mean \pm SD) & $0.77 \pm 0.39$ & $0.84 \pm 1.18$ & $3.59 \pm 1.98$ & $2.04 \pm 2.03$ & $<0.001^{* *}$ \\
\hline Cotinine $(\mathrm{ng} / \mathrm{ml})($ mean $\pm \mathrm{SD})$ & $1.47 \pm 1.06$ & $1.67 \pm 1.77$ & $13.9 \pm 5.26$ & $7.06 \pm 7.16$ & $<0.001^{* *}$ \\
\hline MDA (nmol/ml) (mean \pm SD) & $28.24 \pm 24.82$ & $24.33 \pm 20.09$ & $96.69 \pm 25.22$ & $57.36 \pm 42.37$ & $<0.001^{* *}$ \\
\hline $\mathrm{SOD}(\mathrm{U} / \mathrm{ml})($ mean $\pm \mathrm{SD})$ & $1.79 \pm 0.65$ & $1.88 \pm 0.63$ & $0.62 \pm 0.28$ & $1.3 \pm 0.79$ & $<0.001^{* *}$ \\
\hline TAC (U/ml) (mean $\pm \mathrm{SD})$ & $18.99 \pm 5.47$ & $18.41 \pm 5.97$ & $7.41 \pm 2.2$ & $13.65 \pm 7.19$ & $<0.001^{* *}$ \\
\hline
\end{tabular}

**Highly significant $p<0.001$

8-OHdG 8-hydroxy-2'-deoxyguanosine; MDA malondialdehyde; SOD superoxide dismutase; TAC total antioxidant capacity

$\mathrm{nm}$, the resultant pink color was stable for $6 \mathrm{~h}$ and linearity up to $100 \mathrm{nmol} / \mathrm{ml}$. Malondialdehyde in sample was calculated as follows:

$$
\text { Plasma }=\frac{\text { A sample }}{\text { A standard }} \times 10 \mathrm{nmol} / \mathrm{ml}
$$

\section{Statistical analysis of data}

Microsoft excel 2013 was used for data entry after coding and the statistical package for social science (SPSS) version 21 (SPSS, Armonk, NY: International Business Machines Corporation) was used for data analysis. Simple descriptive statistics (arithmetic mean and standard deviation) were used for summary of quantitative data and frequencies were used for qualitative data. Bivariate relationship was displayed in cross tabulations and

Table 4 Pairwise comparison between the studied groups concerning levels of the measured biochemical parameters

\begin{tabular}{llll}
\hline Dependent variable & Group & Group & $p$ value \\
\hline 8-OHdG $(\mathrm{ng} / \mathrm{ml})$ & Non-smokers & Passive smokers & 0.985 \\
& Active smokers & Non-smokers & $0.000^{* *}$ \\
& & Passive smokers & $0.000^{* *}$ \\
Cotinine $(\mathrm{ng} / \mathrm{ml})$ & Non-smokers & Passive smokers & 0.983 \\
& Active smokers & Non-smokers & $0.000^{* *}$ \\
& & Passive smokers & $0.000^{* *}$ \\
MDA $(\mathrm{nmol} / \mathrm{ml})$ & Non-smokers & Passive smokers & 0.834 \\
& Active smokers & Non-smokers & $0.000^{* *}$ \\
& & Passive smokers & $0.000^{* *}$ \\
SOD $(\mathrm{U} / \mathrm{ml})$ & Non-smokers & Passive smokers & 0.802 \\
& Active smokers & Non-smokers & $0.000^{* *}$ \\
& & Passive smokers & $0.000^{* *}$ \\
& NAC $(\mathrm{U} / \mathrm{ml})$ & Passive smokers & 0.895 \\
& Active smokers & Non-smokers & $0.000^{* *}$ \\
& & Passive smokers & $0.000^{* *}$ \\
& & &
\end{tabular}

**Highly significant $p<0.001$

8-OHdG 8-hydroxy-2'-deoxyguanosine; MDA malondialdehyde; SOD superoxide dismutase; TAC total antioxidant capacity comparison of proportions was performed using the chisquare test. Independent $t$ test, one-way analysis of variance (ANOVA), and post hoc tests were used to compare normally distributed quantitative data. The level of significance was set at probability $(p)$ value $\leq 0.05$ and $p$ value $<0.001$ was considered as highly significant. Correlations between variables were done using Pearson correlation coefficient $(r)$ which was able to describe both correlation direction (positive or negative according to the sign) and power (weak correlation if $<0.5$, moderate correlation from 0.5 and 0.7 and strong correlation if $>0.7$ ) (Dawson and Trapp 2004).

\section{Results}

The current study included 90 male participants, aged 20-60 years, who were interviewed and classified into 3 groups (20 non-smokers, 30 passive smokers, and 40 active smokers). Demographic characteristics of the studied groups were shown in Table 1.There were no statistically significant differences between the studied groups regarding their age and residence whereas, statistically significant differences were detected between the groups concerning their occupation and educational level.

Lifestyle factors of the studied groups were demonstrated in Table 2. No significant difference between exercise-practicing and non-practicing participants was detected. There were increased tea and coffee consumption rates in active smokers with highly significant $(p<0.001)$ and significant $(p=0.052)$ values respectively. Active smokers had the lowest BMI while non-smokers had the highest ones with a highly significant difference between the studied groups ( $p<0.001)$.

As shown in Table 3, there were higher levels of 8OHdG, cotinine, and MDA and lower levels of SOD and TAC in active smokers compared to passive and nonsmokers with a highly significant difference between the studied groups $(p<0.001)$.

When pairwise comparison (post hoc test) was performed, a highly significant difference was detected between active and both passive and non-smokers $(p<0.001)$ whereas, no significant difference between 


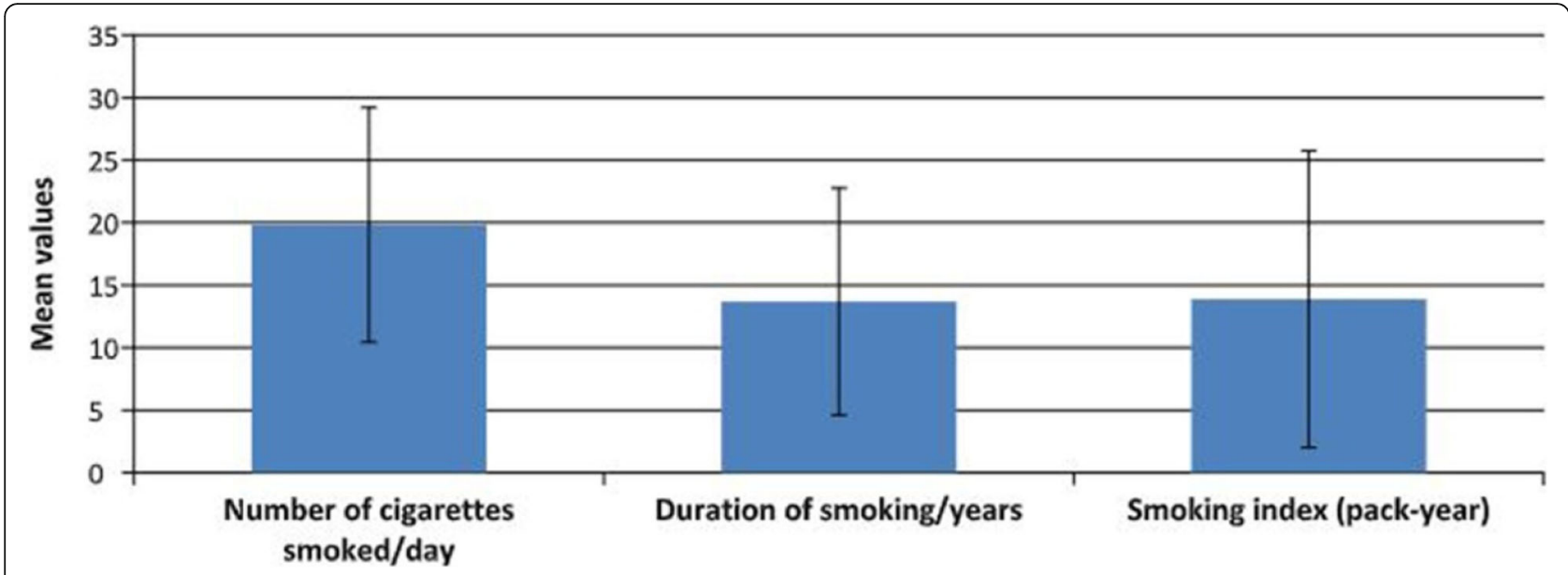

Fig. 1 Mean values of smoking habits in active smokers

passive and non-smokers was observed $(p>0.05)$ (Table 4).

Concerning smoking habits in active smokers, the mean values were provided in Fig. 1.

No significant correlations were observed between 8OHdG level and smoking habits as shown in Table 5.

As shown in Table 6, there were no significant differences between 8-OHdG level and age, exercise, tea and coffee consumption, and BMI among the 3 studied groups $(p>0.05)$.

\section{Discussion}

Oxidative stress caused by tobacco smoke can result in damage to lipids, proteins, and DNA leading to cellular dysfunction or ultimately cell death (Black et al. 2016). Sensitive and specific biomarkers for antioxidant status/ oxidative stress are essential to better understand the role of antioxidants and oxidative stress in human health and diseases (Yeum et al. 2011).

In the current study, active smokers represented $62.5 \%$ and $37.5 \%$ in urban and rural areas respectively. This finding was in agreement with Völzke et al. (2006) who reported the presence of a higher percent of smokers among urban compared to rural communities. This was explained by the more stressful life in urban areas. In contrary, researchers in Canada stated that an increased number of smokers in rural areas may be present due to fewer restrictions concerning smoking (Li et al. 2009).
In the current work, while passing from non- to active smokers, the physical work increased while mental work decreased. These results were in agreement with Kim et al. (2015) who investigated smoking and possible related factors among Korean male workers and found that smoking rate in manual was higher than in non-manual workers due to less effective antismoking policies in manual workers.

In the present study, the percent of active smokers with high educational level was the lowest (7.5\%). These results were in accordance with Han et al. (2010) and may be explained by the fact that high educational level increased the awareness of smoking dangers and reduced environmental and occupational exposure.

In the current work, there was significant increase in tea and coffee consumption rates in active smokers. These results were in agreement with Chao (2015) who stated that non-smokers metabolize caffeine at a lower rate than smokers.

In the current study, active smokers had the lowest BMI. This was attributed to the fact that nicotine is associated with reduced appetite, less efficient absorption and storage of calories and increased thermogenesis (Chiolero et al. 2008).

In the present work, there were highly significant higher levels of 8-OHdG, cotinine, and MDA in active smokers compared to both passive and non-smokers whereas, there was no significant difference between passive and non-smokers. These results were in

Table 5 Correlation between 8-OHdG level and smoking habits in active smokers

\begin{tabular}{|c|c|c|c|}
\hline \multirow[b]{2}{*}{$8-\mathrm{OHdG}(\mathrm{ng} / \mathrm{ml})$} & \multicolumn{3}{|l|}{ Active smokers $(n=40)$} \\
\hline & Number of cigarettes smoked/day & Duration of smoking/years & Smoking index (pack-year) \\
\hline Correlation Coefficient $(r)$ & 0.219 & 0.135 & 0.058 \\
\hline$p$ value & 0.174 & 0.405 & 0.720 \\
\hline
\end{tabular}


Table 6 Comparison between 8-OHdG level and age as well as lifestyle factors among the studied groups

\begin{tabular}{|c|c|c|c|c|c|c|c|c|c|c|c|c|c|c|c|}
\hline \multirow[b]{2}{*}{$\begin{array}{l}\text { 8-OHdG } \\
(\mathrm{ng} / \mathrm{ml})\end{array}$} & \multicolumn{5}{|c|}{ Non-smokers $(n=20)$} & \multicolumn{5}{|c|}{ Passive smokers $(n=30)$} & \multicolumn{5}{|c|}{ Active smokers $(n=40)$} \\
\hline & $\begin{array}{l}\text { Age } \\
\text { (years) }\end{array}$ & Exercise & $\begin{array}{l}\text { Tea } \\
\text { (cups/ } \\
\text { day) }\end{array}$ & $\begin{array}{l}\text { Coffee } \\
\text { (cups/ } \\
\text { day) }\end{array}$ & $\begin{array}{l}\mathrm{BMl} \\
(\mathrm{kg} / \\
\left.\mathrm{m}^{2}\right)\end{array}$ & $\begin{array}{l}\text { Age } \\
\text { (years) }\end{array}$ & Exercise & $\begin{array}{l}\text { Tea } \\
\text { (cups/ } \\
\text { day) }\end{array}$ & $\begin{array}{l}\text { Coffee } \\
\text { (cups/ } \\
\text { day) }\end{array}$ & $\begin{array}{l}\mathrm{BMl} \\
(\mathrm{kg} / \\
\left.\mathrm{m}^{2}\right)\end{array}$ & $\begin{array}{l}\text { Age } \\
\text { (years) }\end{array}$ & Exercise & $\begin{array}{l}\text { Tea } \\
\text { (cups/ } \\
\text { day) }\end{array}$ & $\begin{array}{l}\text { Coffee } \\
\text { (cups/ } \\
\text { day) }\end{array}$ & $\begin{array}{l}\mathrm{BMI} \\
(\mathrm{kg} / \\
\left.\mathrm{m}^{2}\right)\end{array}$ \\
\hline $\begin{array}{l}\text { Correlation } \\
\text { Coefficient } \\
\text { (r) }\end{array}$ & 0.033 & - & 0.252 & 0.249 & 0.061 & -0.200 & - & -0.070 & -0.167 & 0.346 & 0.164 & - & 0.233 & 0.179 & 0.042 \\
\hline$p$ value & 0.889 & 0.536 & 0.285 & 0.290 & 0.797 & 0.288 & 0.621 & 0.713 & 0.377 & 0.061 & 0.312 & 0.192 & 0.148 & 0.269 & 0.796 \\
\hline
\end{tabular}

8-OHdG 8-hydroxy-2'-deoxyguanosine; BMI body mass index

accordance with Lodovici et al. (2005) who conducted a study on lifestyle determinants of 8-OHdG levels in human leukocyte DNA in Italy and stated that 8-OHdG and cotinine levels were higher in active smokers compared to non-smokers; while the difference between passive and non-smokers was not significant. Also, Chávez et al. (2007) measured serum levels of MDA and found that they were higher in smokers than in non-smokers.

Concerning the levels of SOD and TAC, there were highly significant lower levels in active smokers compared to both passive and non-smokers. These results were in accordance with Reddy et al. (2012) where there was a significant decrease in SOD levels of smokers with increased duration and frequency of smoking. However, according to Jenifer et al. (2015), SOD levels were higher in smokers than in non-smokers. Also, the results of this study agreed with Bakhtiari et al. (2015) who conducted a cross-sectional study to investigate the influence of cigarette smoke on salivary TAC. The mean salivary TAC in smokers $(0.529 \pm 0.167 \mathrm{U} / \mathrm{ml})$ was statistically significantly lower than in non-smokers $(0.741 \pm 0.123$ $\mathrm{U} / \mathrm{ml})(p<0.001)$. In contrary, Nagler (2007) showed that salivary TAC was significantly higher in smokers compared to non-smokers.

Discrepancy between the results of the abovementioned studies was explained as follows: increased oxidative stress leads to an induction in the activities of antioxidants as a part of compensatory and defense mechanisms to protect the organism. These mechanisms prevent the accumulation of free radicals present in cigarette smoke and the lipid peroxidation products, such as MDA. At a point, this compensatory effect is overcome and toxic effects are initiated resulting in a decrease in antioxidants (Chávez et al. 2007; Mizrak et al. 2015).

In the current study, there were no significant correlations between 8-OHdG level and smoking habits in active smokers. Similarly, Lodovici et al. (2005) observed no correlation between 8-OHdG levels and the number of cigarettes smoked/day. However, KulikowskaKarpińska and Czerw (2015) estimated urinary 8-OHdG concentration in 63 smokers and 20 non-smokers and found that the increase in 8-OHdG was depended on the amount of smoked cigarettes/day and the duration of smoking.

In the current work, there were no significant correlations between 8-OHdG level and age among the studied groups. These results were in accordance with Lodovici et al. (2005) and Tamae et al. (2009) who studied the influence of age, smoking, and other lifestyle factors on 8OHdG where data from male subjects, $18-60$ years were analyzed. In contrary, Yao et al. (2004) found a significant difference between 8-OHdG level and age ( $p=$ 0.032 ) and concluded that oxidative DNA damage increases with age.

In the present study, there was no significant difference between 8-OHdG and exercise among the studied groups. Similarly, Black et al. (2016) conducted a study on socio-demographic and lifestyle factors of 8-OHdG in the Netherlands and found no significant difference between 8-OHdG level and physical activity.

In the current study, there were no significant correlations between 8-OHdG level and tea and coffee consumption rates among the studied groups. These results were in accordance with Han et al. (2010) where they showed that tea and coffee consumption did not affect urinary 8-OHdG levels. In contrary, Raza and John (2008) demonstrated the effects of tea polyphenols on oxidative stress and concluded that they have protective effect and strong inhibitory activity on the free radicalinduced oxidation.

In the current study, there were no significant correlations between 8-OHdG level and BMI among the studied groups. Similarly, Lodovici et al. (2005), Tamae et al. (2009), Han et al. (2010), and Black et al. (2016) found no significant correlation between 8-OHdGlevel and BMI. However, Kasai et al. (2001) studied the influence of smoking and BMI on urinary 8-OHdG and found a negative correlation between them and explained it by the fact that lean persons have a higher metabolic rate than obese and therefore have higher oxidative stress.

\section{Conclusion}

The results of the current study seem to support the hypothesis that active smoking is associated with increased oxidative stress and decreased antioxidant defense. It 
elevates blood 8-OHdG, a reliable biomarker for oxidative DNA damage. No statistically significant difference between passive and non-smokers was detected in all the biomarkers. There were no significant differences between 8-OHdG level and lifestyle factors among the three studied groups. Hence, it is recommended to strengthen tobacco control measures, promote healthy lifestyle, and conduct further work to further understand which lifestyle factors determine basal oxidative stress and 8-OHdG level as well as to carry out individual exposure assessments instead of relying on the reports of the participants in relation to smoking to further differentiate between passive and non-smokers taking into consideration gender and individual variations as well as methodological and analytical differences. It is also important to investigate the effect of dietary patterns.

\section{Abbreviations}

8-OHdG: 8-hydroxy-2'-deoxyguanosine; ANOVA: One-way Analysis of Variance; BMI: Body mass index; DNA: Deoxyribonucleic acid; ELISA: Enzymelinked immunosorbent assay; ETS: Environmental tobacco smoking; HRP: Horseradish peroxidase; Max.: Maximum; MDA: Malondialdehyde; Min.: Minimum; O.D.: Optical density; P: Probability; PBS: Phosphate-buffered saline; ROS: Reactive oxygen species; SD: Standard deviation; SOD: Superoxide dismutase; SPSS: Statistical Package for Social Science; TAC: Total antioxidant capacity; TBA: Thiobarbituric acid;

TMB: Tetramethylbenzidine; WHO: World Health Organization

\section{Acknowledgements}

None.

\section{Authors' contributions}

MM contributed to the experimental work and writing the paper. EU gave assistance in writing and final revision of the paper. IM helped in the design of the research, starting from the idea, interpretation of results, and revision of the paper. $\mathrm{Gl}$ helped in the final revision of the paper. RL contributed to the laboratory part of the research. All authors read and approved the final manuscript.

\section{Funding}

Cairo University.

\section{Availability of data and materials}

Data will not be shared with public access

\section{Ethics approval and consent to participate}

The study work was conducted after the approval of the Research Ethics Committee, Faculty of Medicine, Cairo University.

\section{Consent for publication}

Consent forms were given and signed by all subjects prior to participation.

\section{Competing interests}

The authors declare that they have no competing interests.

\section{Author details}

${ }^{1}$ Department of Forensic Medicine and Clinical Toxicology, Faculty of Medicine, Cairo University, Cairo, Egypt. ²Department of Medical Biochemistry and Molecular Biology, Faculty of Medicine, Cairo University, Cairo, Egypt.
Received: 22 January 2019 Accepted: 21 May 2019

Published online: 31 May 2019

\section{References}

Aboutaleb N, Jamali H, Abolhasani M et al (2019) Lavender oil (Lavandulaangustifolia) attenuates renal ischemia/reperfusion injury in rats through suppression of inflammation, oxidative stress and apoptosis. Biomed Pharmacother 110:9-19

Andersson KE (2017) Oxidative stress and its possible relation to lower urinary tract functional pathology. BJU Int 120(5):1-15

Antunes-Lopes T, Vasconcelos A, Costa D et al (2018) The impact of chronic pelvic ischemia on LUTS and urinary levels of neuroinflammatory, inflammatory, and oxidative stress markers in elderly men: a case-control study. Urology 123:230-234

Bakhtiari S, Azimi S, Mehdipour M et al (2015) Effect of cigarette smoke on salivary total antioxidant capacity. J Dent Res Dent Clin Dent Prospects 9(4): 281-284

Black CN, Bot M, Scheffer PG et al (2016) Sociodemographic and lifestyle determinants of plasma oxidative stress markers $8-\mathrm{OHdG}$ and F2-Isoprostanes and associations with metabolic syndrome. Oxidative Med Cell Longev 2016: $1-10$

Chao C (2015) The effects of caffeine and smoking. In: Quit \& stay quit Monday. http://www.iquitmonday.org/caffeine-and-smoking/ Accessed 6 July 2015

Chávez J, Cano C, Souki A et al (2007) Effect of cigarette smoking on the oxidant/antioxidant balance in healthy subjects. Am J Ther 14(2):189-193

Chen L, Deng H, Cui H et al (2017) Inflammatory responses and inflammationassociated diseases in organs. Oncotarget 9(6):7204-7218

Chiolero A, Faeh D, Paccaud F et al (2008) Consequences of smoking for body weight, body fat distribution, and insulin resistance. Am J ClinNutr 87(4):801-809

Dawson B, Trapp R (2004) Basic and clinical biostatistics. $4^{\text {th }}$ edn. Mcgraw-Hilllnc, New York

Gao Y, Zhu J, Bao H et al (2018) Effect of lignite fulvic acid on growth, antioxidant ability, and HSP70 of Pacific white shrimp, Litopenaeusvannamei. Aquacultint 26(6):1519-1530

Han Y, Donovan M, Sung F (2010) Increased urinary 8-hydroxy-2'-deoxyguanosine excretion in long-distance bus drivers in Taiwan. Chemosphere 79:942-948

Jenifer HD, Bhola S, Kalburgi V et al (2015) The influence of cigarette smoking on blood and salivary superoxide dismutase enzyme levels among smokers and non-smokers: a cross sectional study. J Tradit Complement Med 5(2):100-105

Kamceva G, Arsova-Sarafinovska Z, Ruskovska T et al (2016) Cigarette smoking and oxidative stress in patients with coronary artery disease. Maced J Med Sci 4(4):636-640

Kasai H, Iwamoto-Tanaka N, Miyamoto T et al (2001) Lifestyle and urinary 8hydroxydeoxyguanosine, a marker of oxidative DNA damage: effects of exercise, working conditions, meat intake, body mass index, and smoking. Jpn J Cancer Res 92(1):9-15

Kim B, Pang D, Park Y et al (2015) Heavy smoking rate trends and related factors in Korean occupational groups: analysis of KNHANES 2007 - 2012 data. BMJ Open 5(11):e008229

Kulikowska-Karpińska E, Czerw K (2015) Estimation of 8-hydroxy-2'deoxyguanosine concentration in the urine of cigarette smokers. WiadLek 68(1):32-38

Li FX, Robson PJ, Ashbury FD et al (2009) Smoking frequency, prevalence and trends, and their socio-demographic associations in Alberta, Canada. Can J Public Health 100(6):453-458

Liu ZH, Cai Y, He J (2018) High serum levels of 8-OHdG are an independent predictor of post-stroke depression in Chinese stroke survivors. Dove Med Press 2018(14):587-596

Lodovici M, Caldini S, Luceri C et al (2005) Active and passive smoking and lifestyle determinants of 8-oxo-7,8-dihydro- 2'-deoxyguanosine levels in human leukocyte DNA. Cancer Epidemiol Biomark Prev 14(12):2975-2977

Lu C, Ma Y, Chen P et al (2014) Oxidative stress of office workers relevant to tobacco smoking and inner air quality. Int J Environ Res Public Health 11:5586-5597

Mahapatra SK, Das S, Dey SK et al (2008) Smoking induced oxidative stress in serum and neutrophil of the university students. Al Ameen J Med Sci 1(1):20-31

Mamsen LS, Lutterodt MC, Andersen EW et al (2010) Cigarette smoking during early pregnancy reduces the number of embryonic germ and somatic cells. Hum Reprod 25(11):2755-2761

Mizrak S, Turan V, Caglayan O et al (2015) The effect of long term pre/postnatal low/high dose nicotine exposure on tissue oxidant/antioxidant status and DNA damage in rats. Drug Res 65:432-436 
Nagler RM (2007) Altered salivary profile in heavy smokers and its possible connection to oral cancer. Int J Biol Markers 22(4):274-280

Raza H, John A (2008) In vitro effects of tea polyphenols on redox metabolism, oxidative stress, and apoptosis in PC12 cells. Ann NY AcadSci 1138:358-365

Reddy S, Swapna LA, Ramesh T et al (2012) Influence of cigarette smoking on blood and salivary superoxide dismutase levels among smokers and nonsmokers. J Investig Clin Dent 3(4):298-303

Rubio CP, Hernández-Ruiz J, Martinez-Subiela S et al (2016) Spectrophotometric assays for total antioxidant capacity (TAC) in dog serum: an update. BMC Vet Res 12(1):166

Tamae K, Kawai K, Yamasaki S et al (2009) Effect of age, smoking and other lifestyle factors on urinary 7-methylguanine and 8-hydroxydeoxyguanosine. Cancer Sci 100(4):715-721

Valavanidis A, Viachogianni T, Fiotakis C (2009) 8-hydroxy-2'-deoxyguanosine (8OHdG): a critical biomarker of oxidative stress and carcinogenesis. J Environ Sci Health C Environ Carcinog Ecotoxicol Rev 27(2):120-139

Völzke H, Neuhauser H, Moebus S et al (2006) Urban-rural disparities in smoking behavior in Germany. BMC Public Health 6:146

World Medical Association (2013) WMA declaration of Helsinki - ethical principles for medical research involving human subjects. $64^{\text {th }}$ WMA general assembly, Fortaleza, Brazil. https://www.wma.net/policies-post/wma-declaration-ofhelsinki-ethical-principles-for-medical-research-involving-human-subjects/. Accessed Oct 2013.

Yao QH, Mei SR, Weng QF et al (2004) Determination of urinary oxidative DNA damage marker 8-hydroxy-2'-deoxyguanosine and the association with cigarette smoking. Talanta 63(3):617-623

Yeum K, Russell R, Aldini G (2011) Antioxidant activity and oxidative stress: an overview. In: Biomarkers for antioxidant defense and oxidative damage. Wiley, Ames, p 3

\section{Publisher's Note}

Springer Nature remains neutral with regard to jurisdictional claims in published maps and institutional affiliations.

\section{Submit your manuscript to a SpringerOpen ${ }^{\circ}$ journal and benefit from:}

- Convenient online submission

- Rigorous peer review

- Open access: articles freely available online

High visibility within the field

- Retaining the copyright to your article

Submit your next manuscript at $\boldsymbol{\nabla}$ springeropen.com 